\title{
Penatalaksanaan impaksi gigi kaninus rahang atas \\ Management of impacted maxillary canine
}

\author{
${ }^{1}$ Anita Septiyani, ${ }^{2}$ M. Hendra Chandha, ${ }^{2}$ Muhammad Ruslin \\ ${ }^{1}$ Dokter gigi \\ ${ }^{2}$ Bagian Bedah Mulut dan Maksilofasial \\ Fakultas Kedokteran Gigi Universitas Hasanuddin \\ Makassar, Indonesia
}

\section{ABSTRACT}

Impacted canines can be detected in early age. The clinicians might be able to prevent them by means of proper clinical diagnosis, radiographic evaluation and timely interceptive treatment. Various surgical and orthodontic techniques can be used to recover impacted maxillary canines. Surgical technique used to manage impacted canines including gingivectomy, apically positional flap, and closed eruption technique. The aim of this review is to provide the management of impacted maxillary canines. Combination between surgical and orthodontic techniques are the effective method to manage impacted maxillary canines with good result.

Key words: management of impacted teeth, impacted maxillary canine

\begin{abstract}
ABSTRAK
Impaksi gigi kaninus dapat dideteksi pada usia muda. Dokter gigi dapat mencegahnya dengan membuat diagnosis klinis yang tepat, evaluasi radiografis dan perawatan pencegahan. Berbagai teknik bedah dan ortodontik dapat digunakan untuk merawat impaksi gigi kaninus RA. Teknik bedah yang digunakan untuk penanganan impaksi gigi kaninus rahang, atas meliputi gingivektomi, flap apikal, dan teknik erupsi tertutup. Tujuan penulisan ini yaitu untuk menentukan penatalaksanaan impaksi gigi kaninus RA. Kombinasi antara teknik bedah dan ortodonsik merupakan metode yang efektif digunakan untuk merawat impaksi gigi kaninus rahang agar diperoleh hasil yang lebih baik.
\end{abstract}

Kata kunci: penatalaksanaan gigi impaksi, impaksi gigi kaninus rahang atas

Koresponden: Muhammad Ruslin, Bagian Bedah Mulut dan Maksilofasial Fakultas Kedokteran Gigi Universitas Hasanuddin Makassar, Jl. Kandea No. 5 Makassar 90135,E-mail: m.ruslin@unhas.ac.id 